Supporting Information

\title{
Omnidirectionally Stretchable Metal Films with Preformed Radial Nanocracks for Soft Electronics
}

\footnotetext{
Seong Won Kim ${ }^{\dagger}$, Siyoung Lee $e^{\dagger}$, Daegun Kim ${ }^{\dagger}$, Seung Goo Lee ${ }^{*,+}$, and Kilwon Cho ${ }^{*}$, †Department of Chemical Engineering and Center for Advanced Soft Electronics, Pohang University of Science and Technology, Pohang 37673, Korea.

Department of Chemistry, University of Ulsan, Ulsan 44610, Korea.

,†e-mail: kwcho@postech.ac.kr

*,*e-mail: lees9@ulsan.ac.kr
} 


\section{Supporting Tables}

\begin{tabular}{ccc}
\hline Solvent & $\begin{array}{c}\text { Solubility parameter } \\
{\left[\delta, \mathrm{cal}^{1 / 2} \mathrm{~cm}^{-3 / 2}\right]}\end{array}$ & $\begin{array}{c}\text { Relative mixing enthalpy } \\
{\left[\left(\delta_{\text {solvent }}-\delta_{\text {PDMS }}\right)^{2}, \mathrm{cal}^{2} \mathrm{~cm}^{-3}\right]}\end{array}$ \\
\hline PDMS & 7.3 & - \\
hexane & 7.3 & 0 \\
diisoproplyamine & 7.3 & 0 \\
toluene & 8.9 & 2.6 \\
1-propanol & 11.9 & 21.2 \\
ethanol & 12.7 & 29.2 \\
\hline
\end{tabular}

Table S1. Solubility parameter and mixing enthalpy of PDMS and organic solvents. 


\section{Supporting Figures}

diisopropylamine

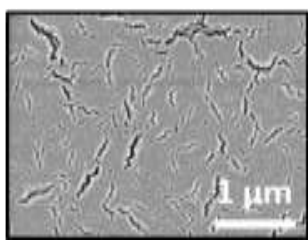

hexane

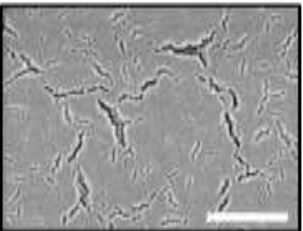

toluene

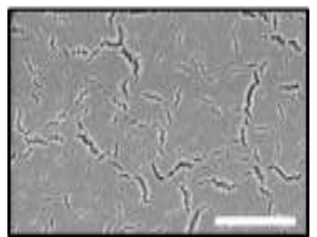

1-propanol

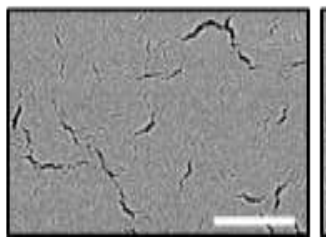

ethanol

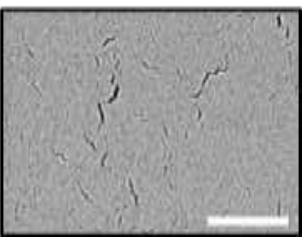

Figure S1. SEM images showing the nanocracked morphology of the gold films $\left(t_{\mathrm{Au}}=50 \mathrm{~nm}\right)$ deposited on the PDMS treated with various solvents.

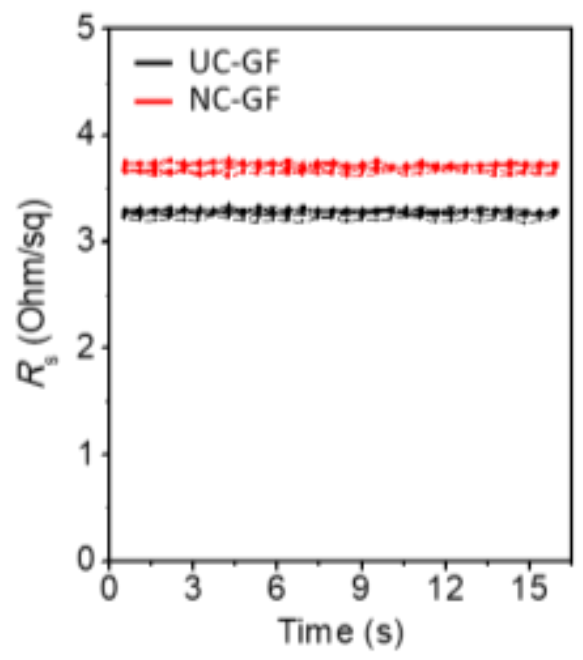

Figure S2. Sheet resistance of the UC-GF and the NC-GF.

(a)

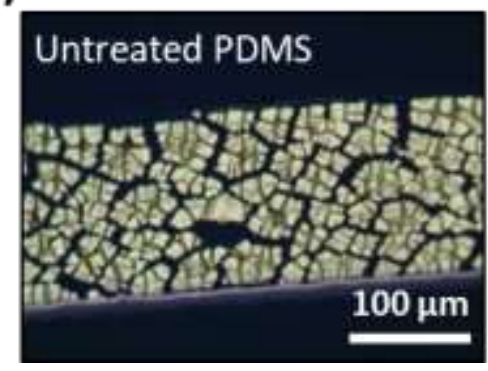

(b)

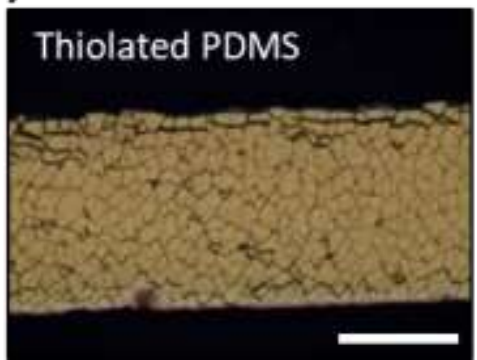

Figure S3. OM images of the gold film deposited on the untreated PDMS a) and the thiolated PDMS b) after immersing in hexane for 1 hour. 

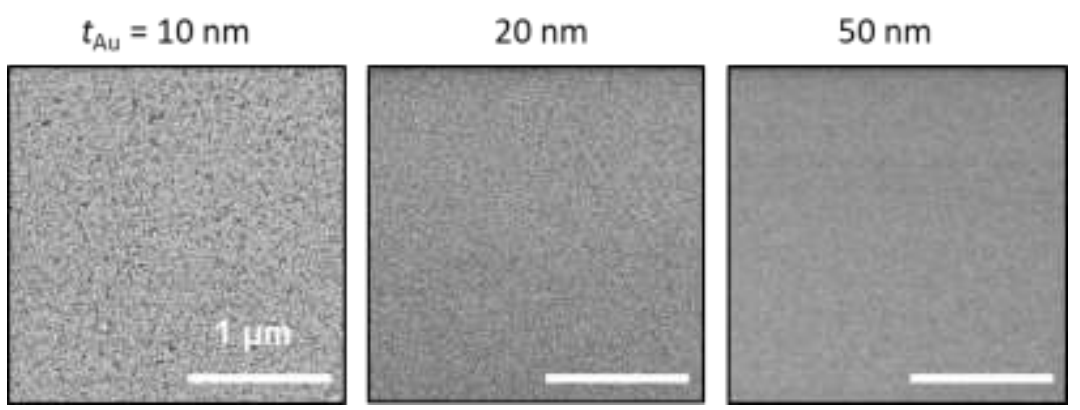

Figure S4. SEM images of the gold film deposited on an untreated PDMS varying with the $t_{\mathrm{Au}}$.

(a)

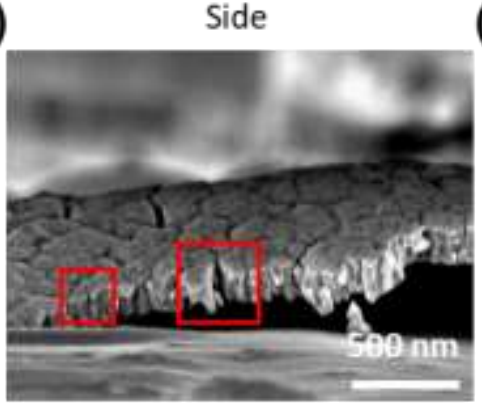

(b)

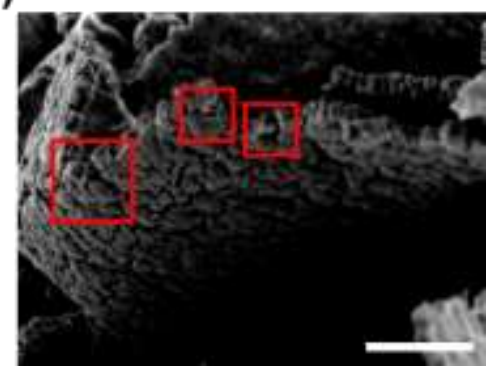

Figure S5. SEM images of the NC-GF at the side a) and the bottom b).

(a)

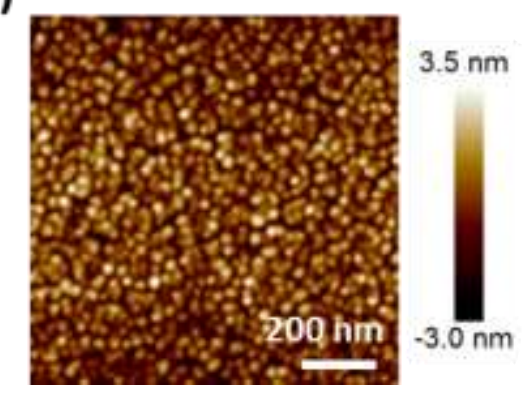

(b)

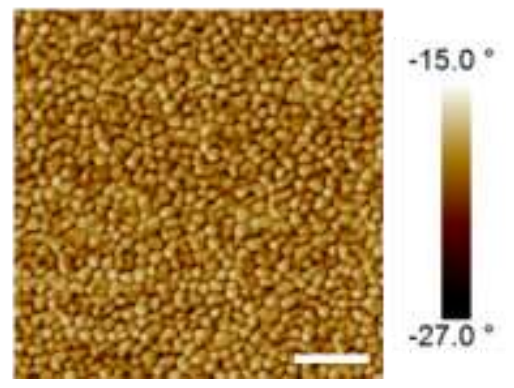

Figure S6. AFM images showing grain size of a gold film deposited on a PDMS film. 


\section{Stress applied on the film during thermal evaporation}

The total stress $\sigma_{\text {total }}$ applied to a deposited thin film during thermal evaporation can be expressed as the sum of thermal stress $\sigma_{\text {th }}$ and internal stress $\sigma_{\text {int. }}$. The $\sigma_{\text {th }}$ is resulted from the difference in thermo-mechanical properties of a substrate and a film, ${ }^{\left[{ }^{[S 1]}\right.}$ and the $\sigma_{\text {int }}$ is resulted from the coalescence of deposited atoms during in-situ growth of a film. ${ }^{[\mathrm{S} 2]}$ The $\sigma_{\text {int }}$ is negligibly smaller than the $\sigma_{t h}$ in our deposition rate $(0.5-1 \AA / \mathrm{s})$, so the $\sigma_{\text {total }}$ can be simplified to the $\sigma_{\text {th }}$ (equation $\mathrm{S} 1)^{[\mathrm{S} 3]}$

When gold is deposited onto a PDMS substrate, the $\sigma_{\text {th }}$ in the gold film is calculated in the range of 0.8 to $0.92 \mathrm{GPa}$ by substituting the deposition temperature $T_{\mathrm{d}}$ (ranges from 60 to $65^{\circ} \mathrm{C}$; thermal label NIGK Corp.), ${ }^{[\mathrm{S} 4]}$ elastic modulus $E$ ( $\sim 50 \mathrm{GPa}$ when the film thickness is less than $100 \mathrm{~nm}),{ }^{[\mathrm{S} 5]}$ thermal expansion coefficients $\alpha$, and Poisson's ratio $v$ into equation (S2). ${ }^{[\mathrm{S} 6]}$

$$
\begin{aligned}
\sigma_{\text {total }} & =\sigma_{\text {th }}+\sigma_{\text {int }} \approx \sigma_{\text {th }} \quad(\mathrm{S} 1) \\
\sigma_{\text {th }}= & \left(\frac{E_{\text {Film }}}{1-v_{\text {Film }}}\right) \varepsilon=\left(\frac{\mathrm{E}_{\text {Film }}}{1-\mathrm{v}_{\text {Film }}}\right) \int_{\mathrm{T}}^{\mathrm{T}_{\mathrm{d}}}\left(\alpha_{\text {substrate }}-\alpha_{\text {Film }}\right) \mathrm{dT} \\
& =\frac{50 \mathrm{GPa}}{1-0.4} *\left(300 * 10^{-6}-24.4 * 10^{-6} \mathrm{~K}^{-1}\right) *\left(T_{d}-298 \mathrm{~K}\right) \\
& =0.80 \mathrm{GPa} \quad\left(\text { At } T_{d}=60{ }^{\circ} \mathrm{C}\right) \\
& =0.92 \mathrm{GPa} \quad\left(\text { At } T_{d}=65{ }^{\circ} \mathrm{C}\right)
\end{aligned}
$$

\section{Critical tensile stress of deposited gold film}

The critical tensile strength of gold $\sigma_{\text {tensile, } 0}$ is about $0.2 \mathrm{GPa} .{ }^{[\mathrm{S} 7]}$ However, critical tensile strength of the deposited film $\sigma_{\text {tensile }}$ is higher than this due to the grain-boundary strengthening effect. ${ }^{[\mathrm{S} 8]}$ Using the Hall-Petch equation which explains the relationship between yield strength $\sigma_{\text {yield }}$ and grain size $d$ (Equation S3), the $\sigma_{\text {yield }}$ of the deposited gold film can be calculated. When the both sides of the equation are divided by yield-to-tensile ratio $R_{\mathrm{y}, \mathrm{t}}$, we can get an equation for the $\sigma_{\text {tensile }}$ (equation S4). By substituting the known Hall-Petch constant $\left(k_{\mathrm{H}}=0.08\right)$, $R_{\mathrm{y}, \mathrm{t}}=0.75,{ }^{[\mathrm{S} 9]}$ and the measured grain size $(d=18 \mathrm{~nm})$ (Figure S6) into the equation $\mathrm{S} 4, \sigma_{\text {tensile }}$ of the gold film is calculated as $0.97 \mathrm{GPa}$. 


$$
\begin{aligned}
\sigma_{\text {yield }} & =\sigma_{y \text { ield }, 0}+\frac{k_{H}}{\sqrt{d}}(\mathrm{~S} 3) \\
\sigma_{\text {yield }} & \times \frac{1}{R_{y, t}}=\left(\sigma_{y i e l d, 0}+\frac{k_{H}}{\sqrt{d}}\right) \times \frac{1}{R_{y, t}} \\
\sigma_{\text {tensile }} & =\left(\sigma_{\text {yield }, 0}+\frac{k_{H}}{\sqrt{d}}\right) \times \frac{1}{R_{y, t}} \\
& =\sigma_{\text {tensile }, 0}+\frac{k_{H}}{\sqrt{d}} \times \frac{1}{R_{y, t}} \\
& =0.2 \mathrm{GPa}+\frac{k_{H}}{\left(18 \mathrm{~nm}^{1 / 2}\right.} \times \frac{1}{0.75} \\
& =0.97 \mathrm{GPa} \quad\left(\mathrm{At} k_{H}=0.08\right)
\end{aligned}
$$

(a)

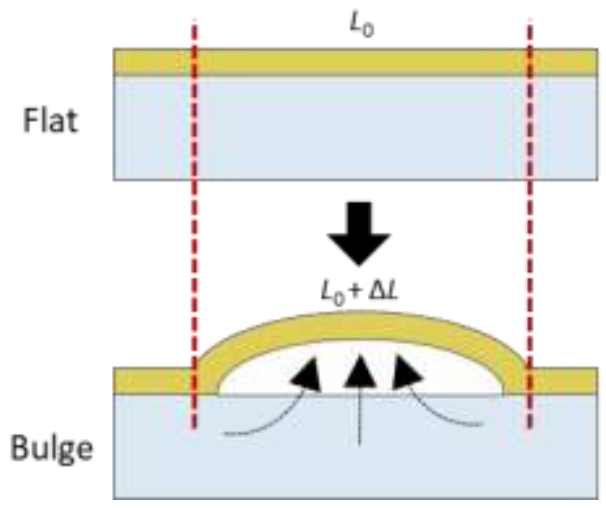

(b)

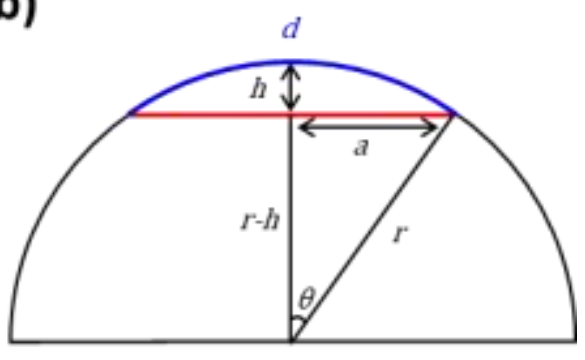

Figure S7. a) Schematics of the bulge in the gold thin film by the solvent eruption. b) A simplified geometric model for the bulge.

\section{Tensile stress applied to bulge region in gold film}

The solvent eruption-induced tensile stress applied to the deposited film ( $\left.\sigma_{\text {erupt }}\right)$ is dependent on the elongation length of the bulge compared to the original flat surface (Figure S7a). To quantify the $\sigma_{\text {erupt, }}$ we established a simplified geometrical model which hypothesizes the bulge region as an arc and the $\sigma_{\text {erupt }}$ as a symmetric in-plane stress (Figure $\mathbf{S 7 b}$ ).

By substituting the values (bulge radius $(a) \sim 1 \mu \mathrm{m}$, bulge height $(h) \sim 0.015 \mu \mathrm{m}$ ) approximated by height profiles of $20 \mathrm{~nm}$ thickness film in AFM images (Figure 2a) into 
equation (S5), the radius of the circle (r) was calculated. Then, the $d$ was calculated by substituting the $\mathrm{r}$ into equation (S6). The applied strain $(\varepsilon)$ to the deposited film can be calculated as below (equation S7). Lastly, by substituting the $E$ and $v$ of gold into equation (S8), the in-plane $\sigma_{\text {erupt }}$ applied to the film is estimated as $3.58 \mathrm{GPa}$.

$$
\begin{aligned}
& r^{2}=(r-\mathrm{h})^{2}+a^{2} \\
& =(r-0.015)^{2}+1^{2} \\
& r=33.342 \mu \mathrm{m} \\
& d=2 \pi r \frac{2 \theta}{360^{\circ}}=2 \pi r \frac{2 \cos ^{-1}\left(\frac{r-0.015}{r}\right)}{360^{\circ}} \\
& =2.085 \mu \mathrm{m} \\
& \varepsilon=\frac{\Delta L}{L_{0}}=\frac{d-2 a}{2 a} \\
& =\frac{(2.085-2) \mu \mathrm{m}}{2 \mu \mathrm{m}} \\
& =0.043 \\
& \sigma_{\text {erupt }}=\left(\frac{E_{A u}}{1-v_{A u}}\right) \varepsilon \\
& =\frac{50 \mathrm{GPa}}{1-0.4} \times 0.043 \\
& =3.58 \mathrm{GPa}
\end{aligned}
$$
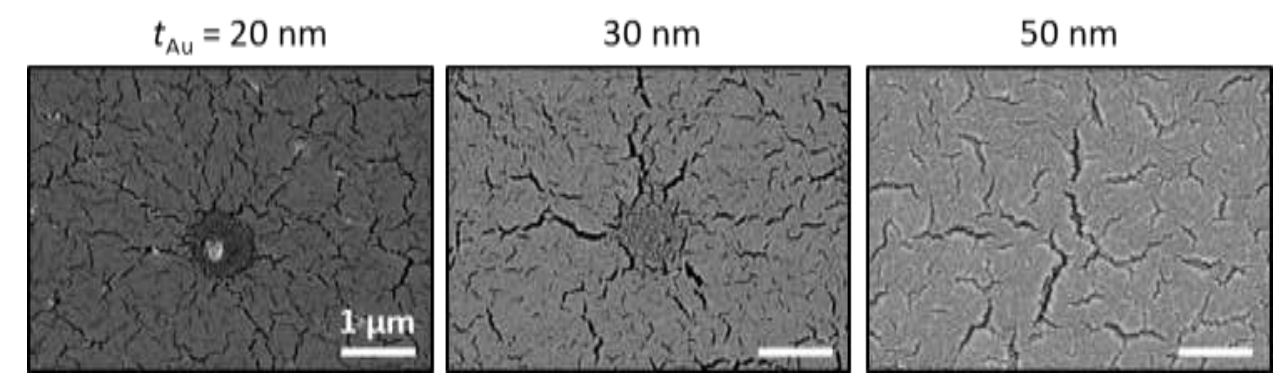

Figure S8. SEM images showing the radial growth of the NC-GF varying with $t_{\mathrm{Au}}$. 


\section{Conditions for cracking}

The occurrence of cracking depends on whether the total stress $\sigma_{\text {total }} \approx \sigma_{\text {th }}$ or the critical tensile stress $\sigma_{\text {tensile }}$ of a film is greater. For the gold film deposited on the PDMS substrate, the $\sigma_{\text {total }}(0.8 \sim 0.92 \mathrm{GPa})$ is smaller than the $\sigma_{\text {tensile }}(0.97 \mathrm{GPa})$ (Inequality $\left.\mathrm{S} 9\right)$; thereby, practical deposited gold films have flat morphology. To induce the cracking in the gold film, an additional stress $\sigma_{\text {erupt }}$ was deliberately added by exploiting the eruption of residual solvent contained in the PDMS substrate during the thermal evaporation process. This additional stress can help the $\sigma_{\text {total }}$ to exceed $\sigma_{\text {tensile }}$ (Inequality S10), so cracking occurs on the gold film that is deposited on the solvent-treated PDMS film. Estimated value of the $\sigma_{\text {erupt }}$ from the bulge geometry is about $3.58 \mathrm{GPa}$, which is much larger than the $\sigma_{\text {tensile. }}$ From these, it is confirmed that the formation of the cracked morphology in the metal film is mainly attributed to the $\sigma_{\text {erupt. }}$.

$$
\begin{aligned}
& \sigma_{\text {total }} \approx \sigma_{\text {th }}<\sigma_{\text {tensile }} \\
& \sigma_{\text {total,solvent }} \approx \sigma_{\text {th }}+\sigma_{\text {erupt }}>\sigma_{\text {tensile }}
\end{aligned}
$$

\section{(a)}

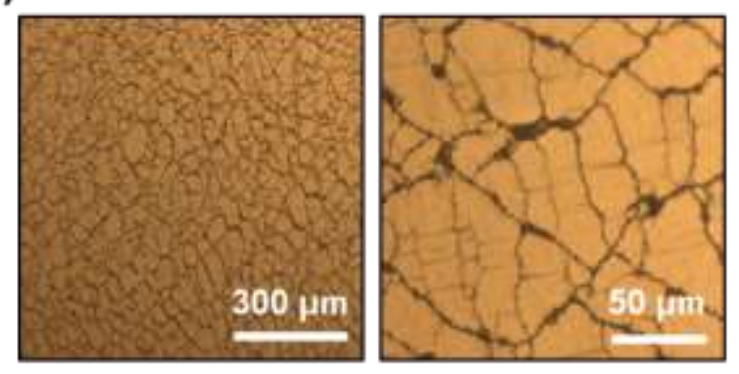

(b)
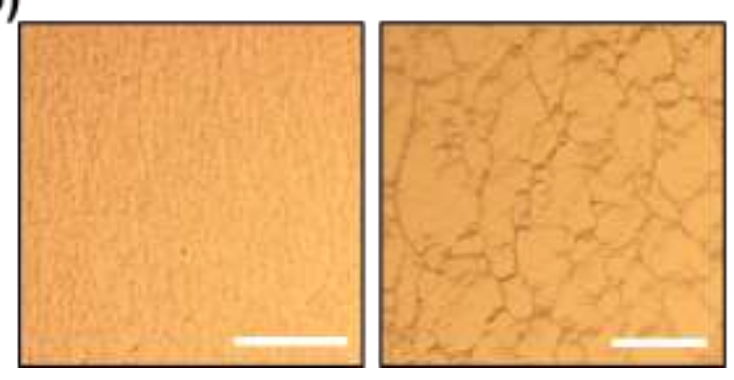

Figure S9. OM images showing the morphology of the UC-GF a) and the NC-GF b) after 1000 repeated cycle stretching at $30 \%$ tensile strain with 500x (left) and 2000x magnification (right). 


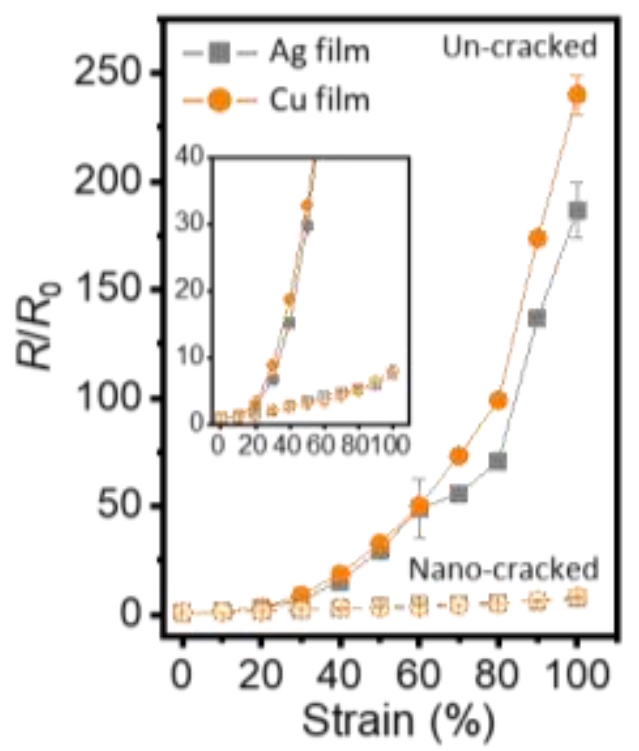

Figure S10. Electrical resistance change $\left(R / R_{0}\right)$ as a function of tensile strain for the UC-SF, UC-CF, NC-SF, and NC-CF.

(a) $\varepsilon=0 \%$ $30 \%$ $50 \%$ $80 \%$
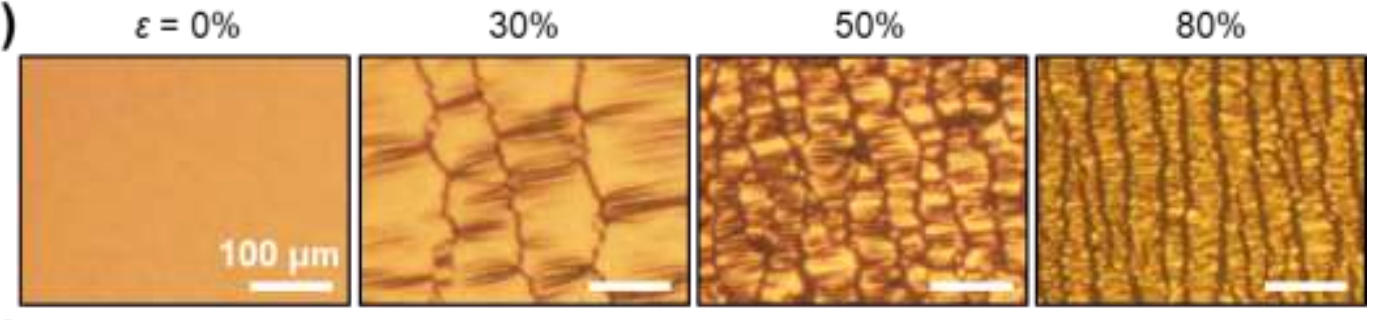

(b)

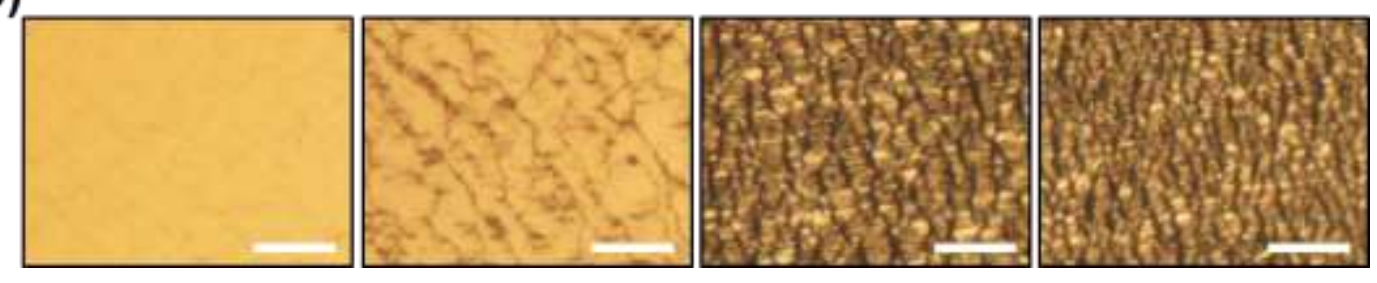

Figure S11. OM images showing macroscale crack propagation of the UC-GF a) and the NCGF b) varying with tensile strain. 

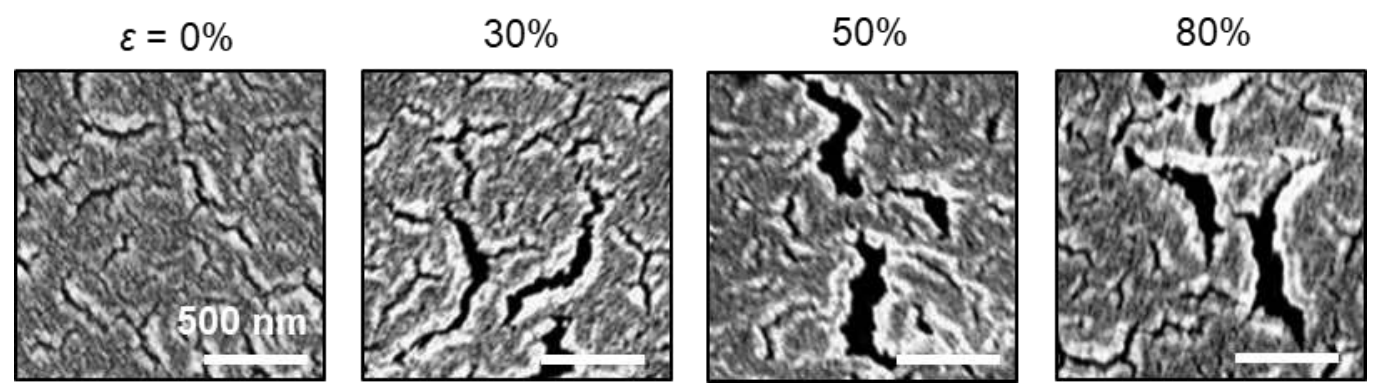

Figure S12. SEM images showing the nanocracks propagation of the NC-GF varying with tensile strain.

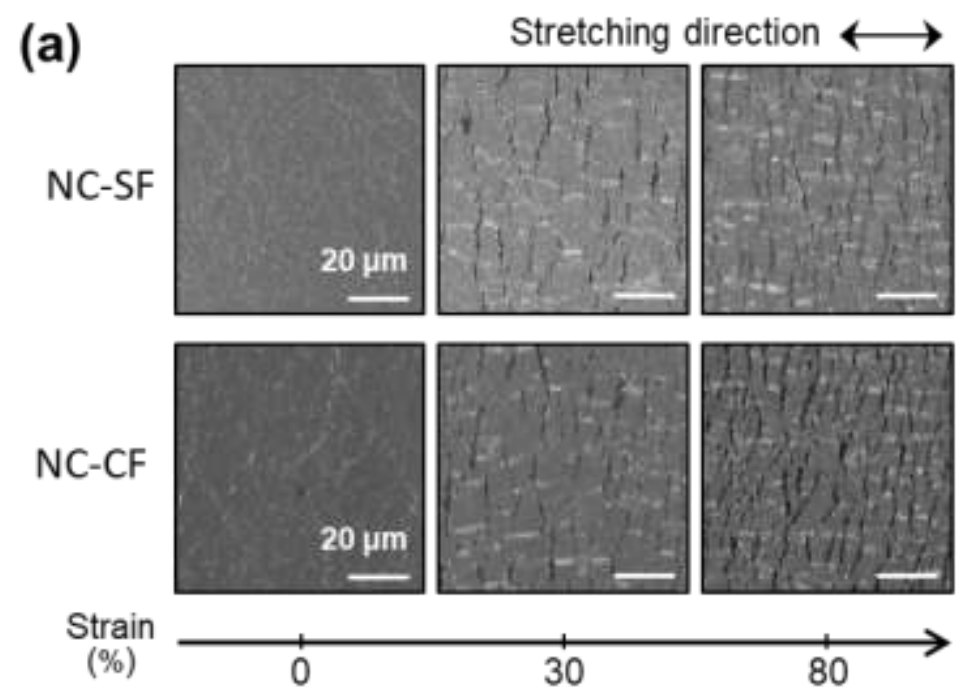

(b)

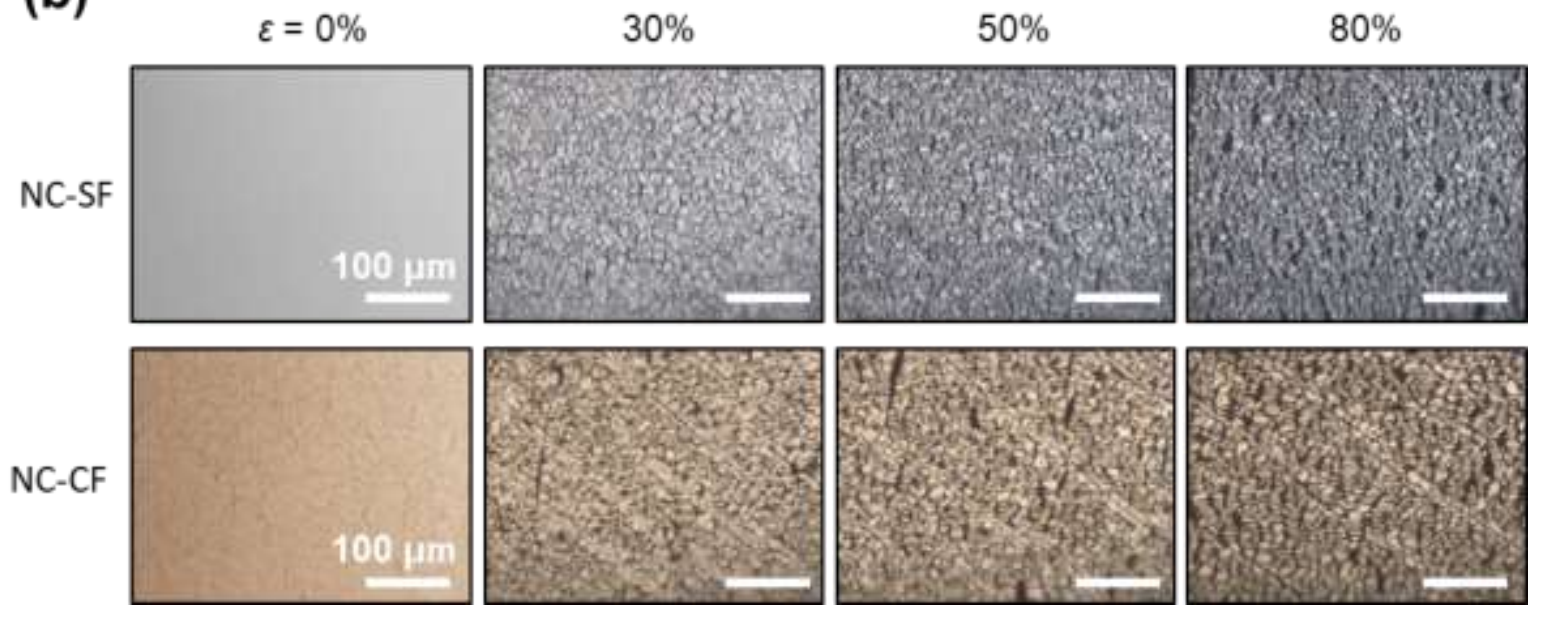

Figure S13. SEM a) and OM b) images of the NC-SF and the NC-CF varying with tensile strain. 

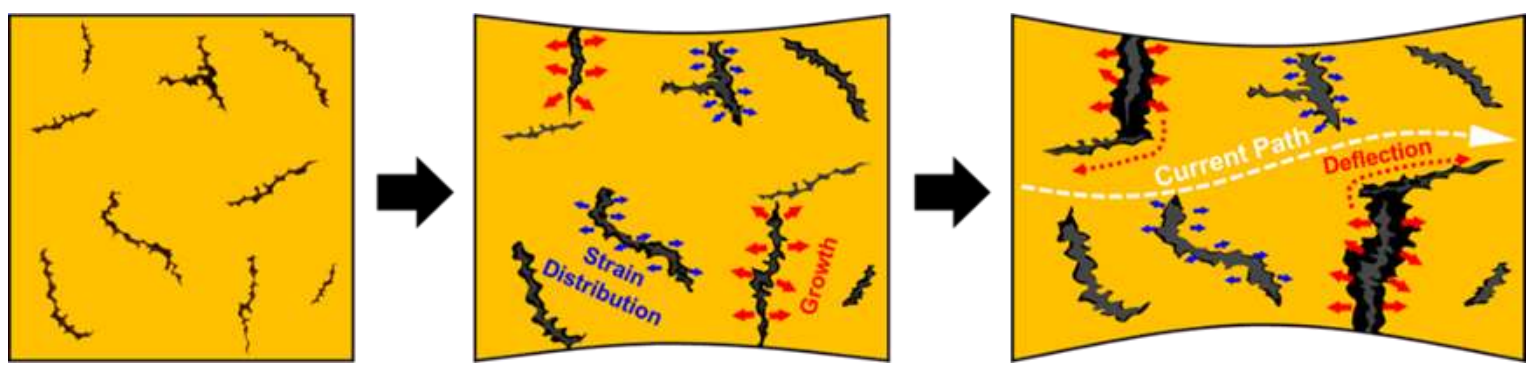

Figure S14. Schematic illustration of crack propagation in the NC-GF under stretching.

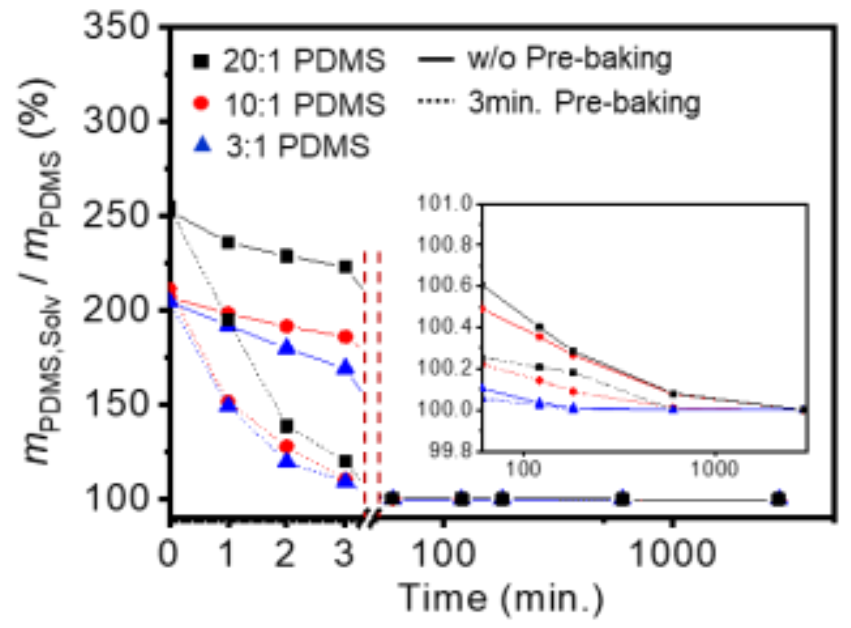

Figure S15. The changes in $m_{\text {PDMS,Solv }} / m_{\text {PDMS }}$ varying with process time after completion of solvent immersion. The inset shows the detailed plots for the time after 60 minutes vacuum in the chamber. 
(a)

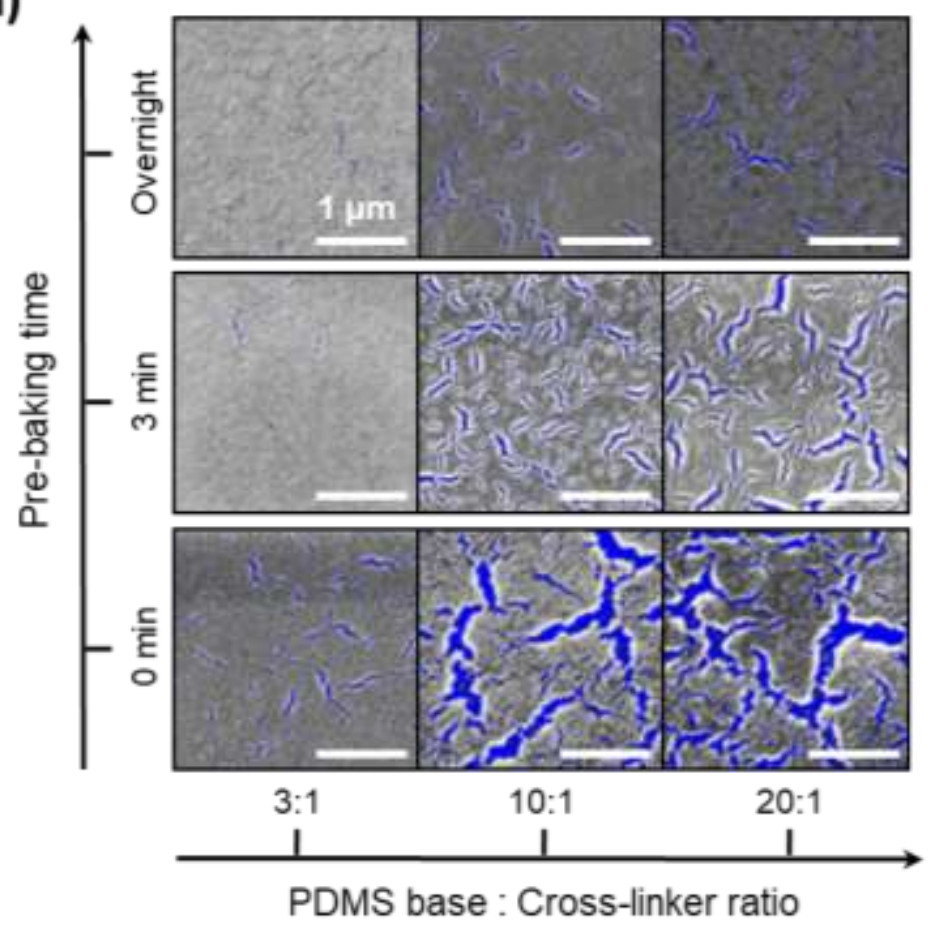

(b)

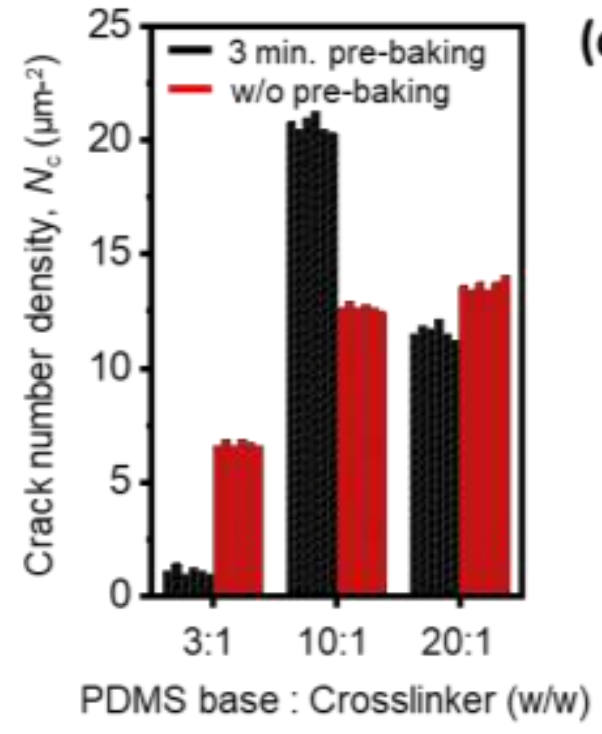

(c)

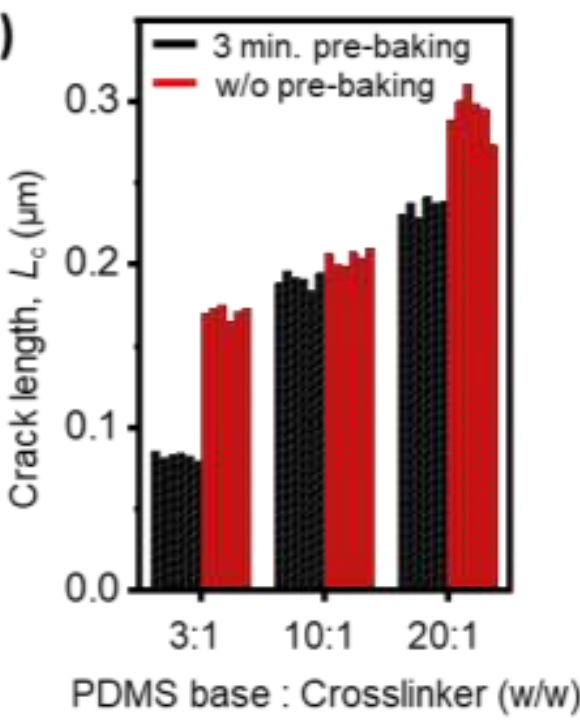

Figure S16. a) SEM images of the NC-GF deposited on the PDMS with residual hexane varying with pre-baking time and crosslinking density. Number density b) and length c) of nanocracks in the gold films $(n=6)$ deposited on the PDMS with residual hexane varying with pre-baking time and crosslinking density. 

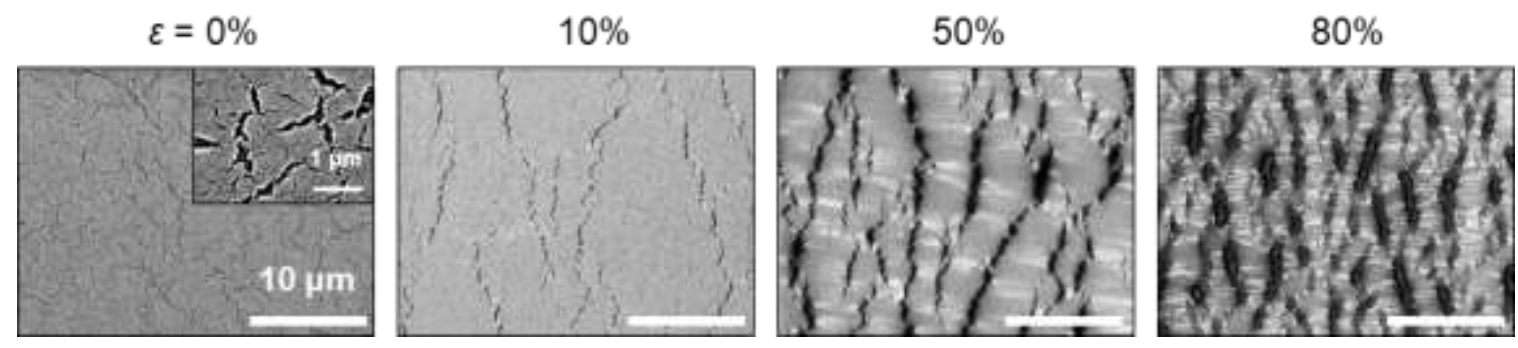

Figure S17. SEM images showing the macroscale crack propagation of the NC-GF $\left(m_{\text {Solv }} / m_{\text {PDMS }}=0.61 \mathrm{wt} \%\right)$ varying with tensile stain .

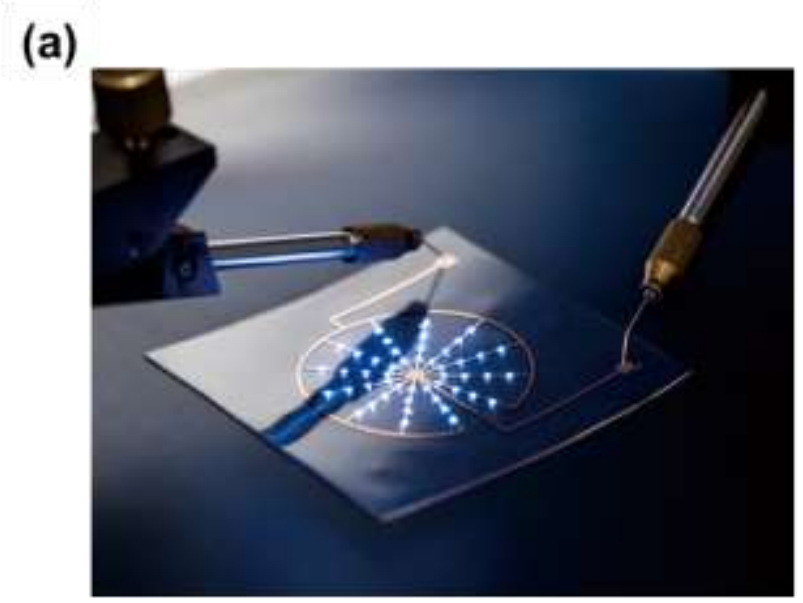

(b)

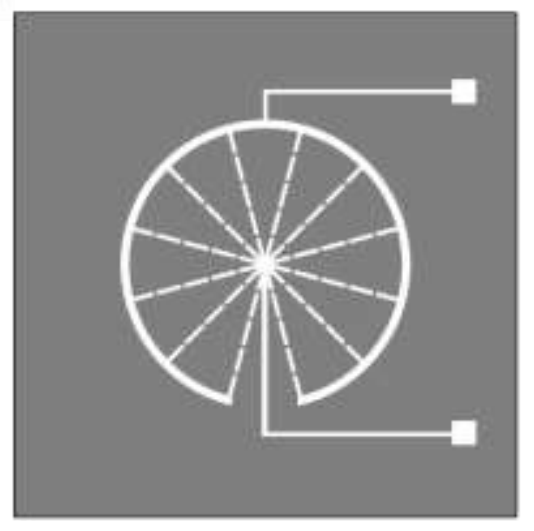

(c)

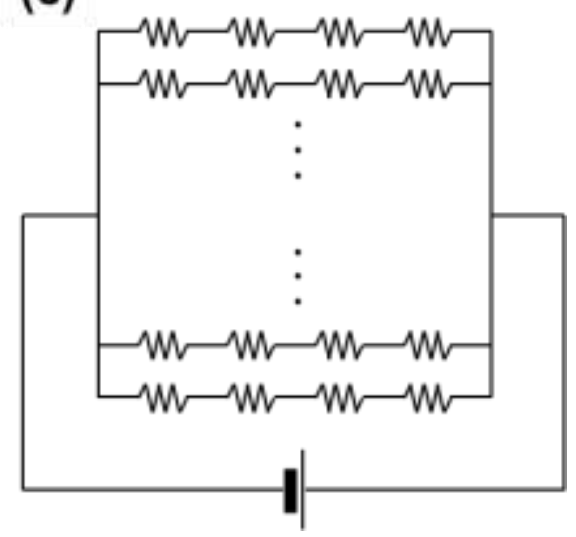

Figure S18. Stretchable interconnects for $4 \times 12$ radial LED array. a) Photograph of the stretchable LED array. b) Schematic illustration of the $4 \times 12$ array. c) Equivalent circuit of the $4 \times 12$ array. 
(a)
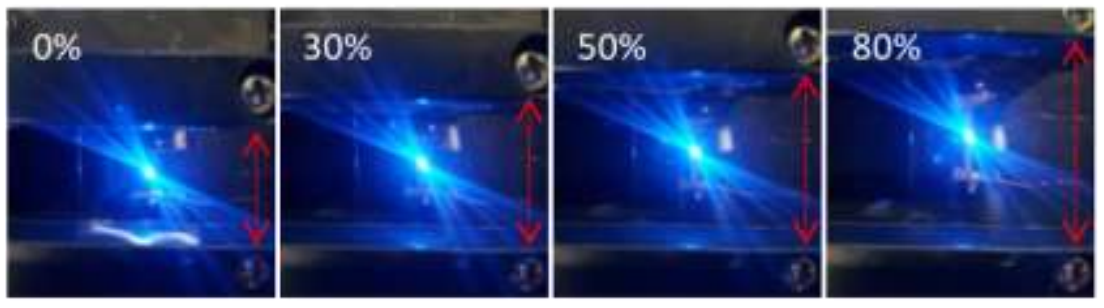

Stretched
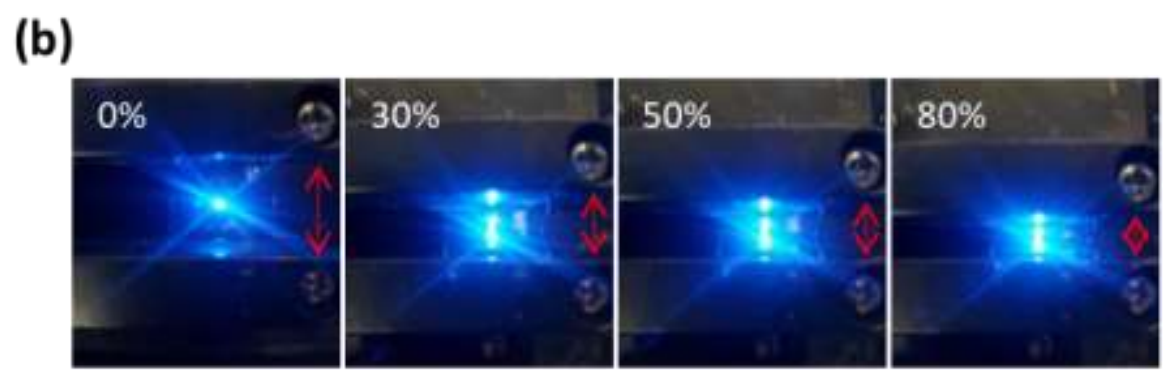

Compressed

Figure S19. Photographs of a single LED varying with applied strain in a stretched state a), and in a compressed state b).

\section{Supporting Movies}

Movie S1. Stretching test for a single LED under 30\% strain.

Movie S2. Compression test for a single LED under 30\% strain.

\section{References}

S1. Jen, S.; Bertrand, J. A.; George, S. M. Critical tensile and compressive strains for cracking of $\mathrm{Al}_{2} \mathrm{O}_{3}$ films grown by atomic layer deposition. J. Appl. Phys. 2011, 109, 084305.

S2. Saedi, A.; Rost, M. J. Thermodynamics of deposition flux-dependent intrinsic film stress. Nat. Commun. 2013, 7, 10733.

S3. Floro, J. A.; Hearne, S. J.; Hunter, J. A.; Kotula, P.; Chason, E.; Seel, S. C.; Thomposn, C. V. The dynamic competition between stress generation and relaxation mechanisms during coalescence of Volmer-Weber thin films. J. Appl. Phys. 2001, 89, 4886-4897.

S4. Graudejus, O.; Gorrn, P.; Wagner, S. Controlling the morphology of gold films on 
poly(dimethylsiloxane). ACS Appl. Mater. Interfaces 2010, 2, 1927-1933.

S5. Birleanu, C.; Pustan, M.; Merie, V.; Muller, R.; Voicu, R.; Baracu, A.; Craciun, S. Temperature effect on the mechanical properties of gold nano films with different thickness. IOP Conf. Series: Materials Science and Engineering 2016, 147, 012021.

S6. Akogwu, O.; Kwabi, D.; Munhutu, A.; Tong, T.; Soboyejo, W. O. Adhesion and cyclic stretching of Au thin film on poly(dimethyl-siloxane) for stretchable electronics. J. Appl. Phys. 2010, 108, 123509.

S7. Nicklaus, M. 2014, Tip-enhanced raman spectroscopy for nanoelectronics (pp. 48).

S8. $\quad$ Blum, W.; Li, Y. J.; Chen, J.; Zeng, X. H.; Lu, K. On the Hall-Petch relation between flow stress and grain size. Int. J. Mater. Res. 2006, 97, 1661-1666.

S9. $\quad$ Cordero, Z. C.; Knight, B. E.; Schuh, C. A. Six decades of the Hall-Petch effect - a survey of grain-size strengthening studies on pure metals. Int. Mater. Rev. 2016, 61, 495-512. 